\title{
Bilateral Chylothorax: An Uncommon Complication of Unilateral Central Venous Catheter Placement
}

\section{Sir,}

Central venous cannulation (CVC) is an invasive procedure routinely being carried out in operating theaters and intensive care units (ICUs) to deliver medications including hyperosmolar drugs, intravenous (I.V.) fluids, hemodialysis, and parenteral nutrition and for monitoring of hemodynamic variables. CVC may result in multiple complications which comprise infection, malpositioning, arterial puncture, local hematoma, pneumothorax, hemothorax, and rarely bilateral chylothorax. ${ }^{[1-3]}$ Chylothorax is the presence of chyle in the pleural space. Chyle consists of lymphatic fluid which is rich in triglycerides, chylomicrons, cholesterol, and fat-soluble vitamins. Etiology of chylothorax in adults is multifactorial with direct trauma $(50 \%)$ and malignancy $(30 \%)$ being the most common. ${ }^{[4]}$ Bilateral chylothorax following left internal jugular vein cannulation is a known entity, but there are hardly any reports of bilateral chylothorax following left subclavian vein cannulation.

A 60-year-old (body mass index: $25.4 \mathrm{~kg} / \mathrm{m}^{2}$ ) male patient underwent subtotal glossectomy with bilateral modified radical neck dissection with a free radial forearm flap reconstruction for carcinoma tongue under general anesthesia (GA). Preanesthetic assessment was normal. Written informed consent was obtained and nil per oral status was confirmed. Standard monitoring ensued. The patient was co-induced with I.V. injection of glycopyrrolate $0.2 \mathrm{mg}$, injection fentanyl $100 \mu \mathrm{g}$, and injection propofol $100 \mathrm{mg}$. The airway was secured under vision with a size 7.0-mm ID cuffed flexometallic endotracheal tube following administration of injection atracurium $25 \mathrm{mg}$. The left subclavian vein was chosen for CVC, to prevent hampering access to the surgical field, and was cannulated using the landmark technique. Intraoperative hypotension was managed with blood, fluids, and infusion of injection noradrenaline $(0.08 \mathrm{mcg} / \mathrm{kg} / \mathrm{min})$. Tracheostomy was done before completion of surgery using an 8.0-mm ID cuffed tracheostomy tube in anticipation of difficult airway access and postoperative mechanical ventilation. The rest of the operative period was uneventful. The patient was not reversed and transferred to ICU for postoperative mechanical ventilation. Noradrenaline was gradually tapered down over the next $24 \mathrm{~h}$. Postoperative period (POD) was uneventful till the $3^{\text {rd }}$ day when sanguineous discharge mixed with chyle $(1000 \mathrm{ml})$ was noticed from the left neck drain. X-ray chest revealed a left pleural effusion, and ultrasound (USG)-guided diagnostic tap revealed a turbid fluid of approximately $10 \mathrm{ml}$. Chylothorax was confirmed by the placement of left intercostal drain which drained a chyle-stained fluid of more than $1000 \mathrm{ml}$. The patient was initiated on total parenteral nutrition, medium-chain triglycerides, antibiotic cover, and injection octreotide $200 \mathrm{mg}$ I.V. 8 hourly ${ }^{[5]}$ The patient continued to drain chyle $(700-800 \mathrm{ml})$ on PODs 4 and 5. On POD 6, in view of diminished breath sounds on the right side, bedside USG was carried out which revealed around $1600 \mathrm{ml}$ of fluid, following which a right-sided intercostal drain was placed [Figure 1]. Both drains continued to drain around $800-900 \mathrm{ml}$ of chyle every day. Conservative management failed to stop the chyle drainage; therefore, surgical repair was planned. On POD 13, the patient was taken up for thoracic duct repair under GA. The leak was identified and ligated. Postoperative recovery was uneventful, and the patient was discharged after 10 days.

Reports of chylothorax due to central venous catheterization in literature are infrequently described even though there is close anatomical proximity between the lymphatic and venous systems. ${ }^{[4]}$ The most common mechanisms for chylothorax development are generally catheter-induced intrinsic thrombosis of the lymphatic-venous system, direct trauma of the thoracic duct, or extrinsic venous compression from the extravasated fluid. ${ }^{[4]}$ The cause of bilateral chylothorax in our patient was most likely due to direct injury of the thoracic duct during left subclavian vein cannulation.

In conclusion, a bilateral chylothorax is a rare but potential complication of left-sided placement of a CVC. Unfortunately, a correct positioning of the $\mathrm{CVC}$, as shown by chest X-ray or ultrasound, does not exclude injury of the thoracic duct and development of chylothorax at a later stage. Therefore, adequate precautions must be taken, and suspicion of this unlikely complication should be kept in mind.

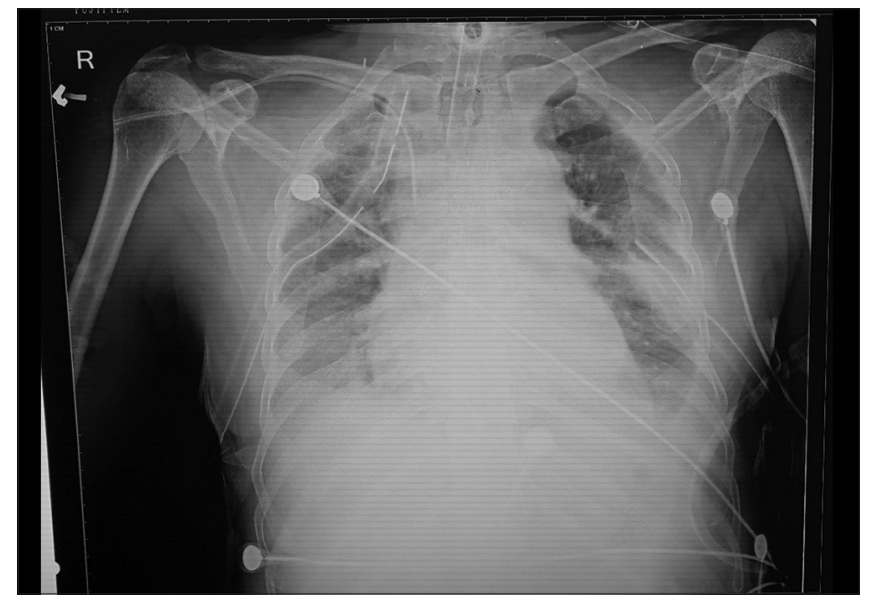

Figure 1: The presence of right and left chest drains before surgical repair of the thoracic duct 


\section{Declaration of patient consent}

The authors certify that they have obtained all appropriate patient consent forms. In the form the patient has given his consent for his images and other clinical information to be reported in the journal. The patient understands that his names and initials will not be published and due efforts will be made to conceal his identity, but anonymity cannot be guaranteed.

\section{Financial support and sponsorship}

Nil.

\section{Conflicts of interest}

There are no conflicts of interest.

Shalendra Singh, Venigalla Sri Krishna, Saurabh Sud ${ }^{1}$, Deepak Dwivedi ${ }^{1}$ Department of Anaesthesia and Critical Care, Armed Forces Medical College, 'Department of Anaesthesia and Critical Care, Command Hospital (Southern Command), Pune, Maharashtra, India

Address for correspondence: Dr. Saurabh Sud, Department of Anaesthesia and Critical Care, Command Hospital (Southern Command), Pune - 411 040, Maharashtra, India. E-mail: saurabhsood1975@gmail.com

\section{References}

1. Patel AR, Patel AR, Singh S, Singh S, Khawaja I. Central line catheters and associated complications: A review. Cureus 2020;11:e4717.

2. Mishra N, Singh S, Elayat A, Kaushal A. Cardiac arrest in the prone position caused by central venous cannulation-induced cardiac tamponade. Korean J Anesthesiol 2020;72:394-5.
3. Datta R, Purohit G, Agrawal J, Singh S. Pericardial tamponade: Rare complication of subclavian vein cannulation. Med J Armed Forces India 2018;74:294-6.

4. Nikbakhsh N, Zamani M, Noorbaran A, Naghshineh A, Rastergar-Nejad D. Etiological approach of chylothorax in Babol, Northern Iran. Caspian J Intern Med 2017;8:30-4.

5. Schild HH, Strassburg CP, Welz A, Kalff J. Treatment options in patients with chylothorax. Dtsch Arztebl Int 2013;110:819-26.

This is an open access journal, and articles are distributed under the terms of the Creative Commons Attribution-NonCommercial-ShareAlike 4.0 License, which allows others to remix, tweak, and build upon the work non-commercially, as long as appropriate credit is given and the new creations are licensed under the identical terms.

\begin{tabular}{|l|l|}
\hline \multicolumn{2}{|c|}{ Access this article online } \\
\hline Quick Response Code: & Website: \\
& www.ijrconline.org \\
\hline
\end{tabular}

How to cite this article: Singh S, Krishna VS, Sud S, Dwivedi D. Bilateral chylothorax: An uncommon complication of unilateral central venous catheter placement. Indian J Respir Care 2020;9:240-1.

Received: $13-01-2020$

Revised: 13-03-2020

Accepted: $14-03-2020$

Published: 19-06-2020

(C) 2020 Indian Journal of Respiratory Care | Published by Wolters Kluwer - Medknow 